\title{
Exploring EFL Teachers' and Students' Perceptions of Learner Autonomy in Egyptian Technical Schools
}

\author{
Safaa Mostafa Khalil \\ Dept. of Languages, Sadat Academy for Management Sciences \\ 151 Maadi Al Khabiri Al Wasti, Al Maadi, Cairo 12411, Egypt \\ Tel: 201-067-954-579Ｅ-mail: safaamkhalil@yahoo.com
}

\begin{abstract}
Amira Desouky Ali
Dept. of Languages, Sadat Academy for Management Sciences

151 Maadi Al Khabiri Al Wasti, Al Maadi, Cairo 12411, Egypt

Tel: 201-228-232-012Ｅ-mail: amora.desouky@gmail.com
\end{abstract}

Received: July 3, 2018 Accepted: July 18, 2018 Published: July 22, 2018

doi:10.5296/ijele.v6i2.13408 URL: https://doi.org/10.5296/ijele.v6i2.13408

\begin{abstract}
This study aimed at exploring the perceptions of learner autonomy of 265 students and $89 \mathrm{EFL}$ teachers in technical secondary schools in Egypt. Both qualitative and quantitative data were collected through student questionnaire, teacher questionnaire, and teacher interviews. The findings revealed that the participants; students and teachers, have positive views about learner autonomy in language learning. Students were generally aware of the autonomy-boosting practices and teachers' roles in fostering autonomy. Students were neutral about their ability to choose course materials and use appropriate strategies to learn English. The results also showed that EFL teachers had clear understanding of the concept of learner autonomy and were mostly aware of its importance in EFL classes. However, they perceived their students as non-autonomous due to individual and institutional challenges. Both students and teachers were unsure about the relation between cultural backgrounds and autonomy in language learning. Based on the results, some pedagogical implications and recommendations for future research for promoting learner autonomy in secondary technical schools have been provided.
\end{abstract}

Keywords: Learner autonomy, perceptions, secondary technical education, EFL context, mixed-methods 


\section{Introduction}

In the information age, learner autonomy has become a critical skill for students and teachers to improve their language learning/teaching experiences. English as a Foreign Language (EFL) teachers should train learners on how to develop English learning to be able to compete and succeed in today's growing world. In order for language learners to be autonomous, they have to possess fundamental characteristics. Hasim and Zakaria (2015) believe that in autonomous language learning environment learners:

- learn to be responsible for their learning;

- learn to be self-directed and make decisions about their learning;

- are autonomous individually or within groups; and

- focus on being independent and collaborative.

Benson (2011) states that autonomous learners are those who have control over their decisions concerning determining objectives and content, selecting method, monitoring and evaluation. Research show that such learners involve more actively in the classroom and are more capable of expanding language learning chances outside class (Çakıcı, 2015; Khoshsima \& Rezaeian 2015).

\section{Review of Literature}

\subsection{Learner Autonomy}

The term "Autonomy" comes originally from the Greek word "autonomos" where auto means self and nomos means law. In foreign language learning and teaching, the term was first introduced by Holec in 1979. He gave a key definition to autonomy as 'the ability to take charge of one's own learning' (Benson, 2011, p.58). Based on Holec's view, various definitions of learner autonomy have been introduced. All definitions share the view that learner autonomy advocates learners' freedom to make their own choices and decisions in learning (Benson, 2012). Learners' independency involves activities that enhance the learning process such as setting goals, self-reflection and self-evaluation (Tran \& Duong, 2018).

Researchers add psychological and social dimensions that lead to learner autonomy and resulted from it. Benson's view is that autonomy is developed within what he called "a mutual contract in which each individual agrees to provide the social goods that support the autonomy of others" (2012, p. 32). Benson (2012) identifies three dimensions of learner autonomy: technical, psychological, and political. The technical dimension is concerned with the strategies and skills the learners use in order to be self-directed. The psychological dimension refers to the individual behaviors and abilities that enable the learner to be autonomous. Finally, political autonomy manifests the distribution of power among participants in the learning process; the teacher and the learners. This means that teachers allow learners the opportunity to set their goals and to have a 'voice' (Lamb, 2010; Benson 2012). In their attempt to design a comprehensive questionnaire that assesses language teachers' beliefs and practices regarding learner autonomy, Borg and Al-Busaidi (2012) coincide with Benson's dimensions of autonomy. Furthermore, they explored other constructs of debate such as the effect of age, 
culture and proficiency, teacher's role in autonomy, and whether autonomy is innate or capacity.

\subsection{Teacher's Role in Learner Autonomy}

Autonomous learning doesn't mean learning without a teacher. Nevertheless, it contradicts teachers' role as an 'omniscient causer of learning or someone to listen to or obey blindly; rather they are resource to give advice, help learners find material, suggest procedures' (Yasmin \& Sohail, 2018, p. 154). The role of the teacher in fostering learner autonomy has been highlighted by various researchers in past and recent studies (Lamb, 2010; Jácome, 2012; Ikonen, 2013; Han, 2014; Çakıc1, 2015). They agree upon the idea that successful learning depends on a learner-centered environment in which the teacher is a facilitator and a guide (Han, 2014; Çakıc1, 2015). In such environment, the teacher shifts some power to the learners in order to enable them develop their independency. In addition, teachers are considered responsible for teaching strategies (such as planning, monitoring and evaluating) that help enhance learners' autonomy, boost their metacognitive skills, and enhance their personality so that they can 'fight for their rights' (Jácome, 2012, p. 149).

Han (2014) argues that in order to develop learner autonomy, language teachers should possess the knowledge or competences to develop learner autonomy themselves. Autonomous teachers are more capable of integrating autonomy-supportive activities in the classroom. A view that is supported by various studies based on the belief that one cannot teach what he doesn't know (Akbarpour-Tehrani \& Mansor, 2012; Ikonen, 2013; Cubukcu, 2016; Ertürk, 2016; Alonazi, 2017; Tran \& Duong, 2018).

\subsection{Technical Education in Egypt}

Technical education in Egypt is demand-driven rather than supply-driven; producing skilled workforce required for economic growth. The role of the Technical and Vocational Education and Training (TVET) in Egypt is crucial as it prepares and qualifies manpower to meet the growing needs of the labor market to sustain human development and economies (Loveluck, 2012).

Secondary education in Egypt has two routes; general secondary that leads to university and technical secondary that ends with a vocational diploma or leads to technical higher institutions. If students complete compulsory basic education (primary \& preparatory) with high grades, they proceed to general secondary schools; but if they fail to get high results, they pursue the technical track to study a 3-year technical diploma or a 5-year advanced diploma in four specializations: industrial, commercial, agricultural and hospitality and hotels (UNESCO, 2012; EP-Nuffic, 2015). According to the statistical yearbook for the academic year 2017/2018, about $40.6 \%$ of the students who succeed in Basic Education Exam joined technical schools in the four specializations as depicted in Figure 1. 


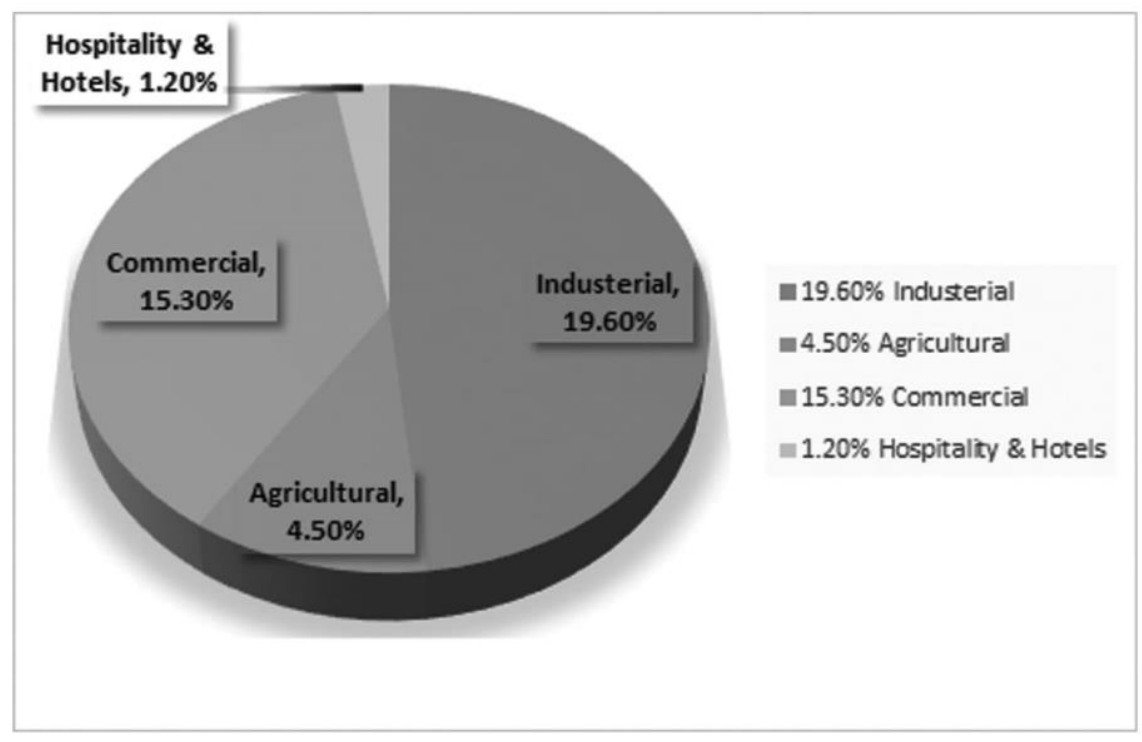

Figure 1. Proportion of students joined technical schools in 2017/2018

Technical education system in Egypt is very complex with 17 ministries involved including Ministry of Education and Ministry of Higher Education; which causes incoordination and misuse of resources (Handoussa, 2010). Technical school teachers complain from low salaries, low status and inferior image of technical education teachers, insufficient facilities and resources for practical training, large class sizes, inadequate development of teachers in terms of content and practicality, and lack of career support and adequate preparation especially for technical teachers and practical trainers (European Commission, 2014). Moreover, technical education students report lack of proficient teachers, outdated curriculum, gap between their expectations/capacities and the requirements of the market, and ineffective teaching methods (Euromonitor International, 2012).

Since 2003/2004, English was introduced in Egyptian primary stage rather than preparatory stage as a mandatory subject; which mandates a shift from the traditional method to the communicative approach in EFL teaching. Several recognized agencies like U.S. Agency for International Development (USAID) and the British Council have collaborated with some national ministries to improve EFL teachers' teaching and training skills and develop language education (Ibrahim \& Ibrahim, 2017).

Students at technical schools study ESP (English for Specific Purposes) courses related to their specializations. However, graduates of this system fail to undertake basic communication in English; therefore struggle to find employment opportunities. This can be attributed to the negative attitudes toward technical and vocational education in Egypt, limited funding and poor quality of education (Loveluck, 2012).

\subsection{Previous Studies}

Numerous studies have investigated students' perceptions and beliefs of learner autonomy. Few studies explored teachers' understanding of learner autonomy and how it is mirrored on 
their teaching practices. While the majority of research addressed tertiary level or secondary stage at public schools or language centers, a small number of studies have investigated learner autonomy at technical or vocational schools. Therefore, the present study fills this gap in research.

Borg and Al-Busaidi (2012) investigated the perceptions of 61 teachers of English regarding learner autonomy at a university in Oman using questionnaires and interviews. Findings highlighted the strategies and skills that teachers believed to be useful in improving individual learning. Al Asmari (2013) and Duong (2014) explored EFL teachers' understanding and practices of learner autonomy. It was concluded that teachers believed that learners should have freedom to make decisions and be active in their EFL learning. However, they agreed that it is difficult to implement practices that support autonomy in English classes.

Alibakhshi, Keikha, and Nezakatgoo, (2015), and Szőcs (2015) adopted Borg and Busaidi's instrument and methodology to examine the perceptions of Iranian, Hungarian and Cypriot EFL teachers regarding learner autonomy. The studies showed positive attitudes of teachers toward learner autonomy. Additionally, Shahsavari (2014) and Parmis (2015) investigated learners' perceptions of autonomy and findings revealed that although both learners and teachers perceived learner autonomy positively, teachers agreed that it is unfeasible to involve learners in every decision.

On the other hand, Nguyen (2014) conducted a case study investigating Vietnamese teachers' beliefs and practices of learner autonomy. Outcomes showed that teachers lacked clear understanding about learner autonomy; which was reflected in their teacher-centered practices. The researcher emphasized the influence of the local and contextual environment in fostering learner autonomy.

Yunus and Arshad (2015) examined the attitudes of 35 teachers toward learner autonomy in language learning in Malaysian public secondary schools. Similarly, Najmeh et al. (2015) observed the practices of 42 instructors and interviewed 19 in Iranian schools to identify the autonomous strategies. Both studies showed positive attitudes and the second study highlighted some techniques to develop autonomy.

Moreover, Alhaysony (2016) conducted a mixed-method study on 77 EFL teachers at Aljouf University in Saudi Arabia to explore their viewpoints of learner autonomy. The researcher found that the majority of participants had positive impression about the importance of autonomy and students' responsibility of and involvement in their language learning. However, participants were less feasible about involving students in decision-making regarding assessment, objectives of a course and material used. Likewise, Doğan and Mirici (2017) investigated 96 EFL teachers' perceptions and practices on learner autonomy at the schools of foreign languages in Turkey. The study showed that the teachers had highly positive perceptions on autonomy. On the contrary, they were less positive about learners' capacities to learn independently.

In his mixed-method study, Arfae (2017) explored the perceptions of ESL teacher trainers, instructors, and learners in the University of Western Ontario. The researcher examined the 
perceptions, desirability, feasibility, and challenges of enhancing learner autonomy. Participants were generally positive about the concept of autonomy and their roles to foster it. They were indefinite about feasibility of autonomy due to institutional and individual barriers. Additionally, Zou (2017) administered a questionnaire on 150 students in Leshan Vocational and Technical College in China to identify participants' awareness of English autonomous learning, strategies to promote autonomy, and barriers of fostering autonomous learning in English learning and their causes. The researcher concluded that the lack of motivation, confidence, appropriate learning strategies, and flexible vocational education system contribute to the weakness of vocational students' English autonomous learning ability.

In accordance with the above literature, the present study aimed at answering the following questions:

1. How do Egyptian students in technical schools perceive autonomy in language learning?

2. How do Egyptian EFL teachers perceive autonomy in technical schools?

3. To what extent are technical school EFL students autonomous? What are the reasons?

4. What are the challenges that face technical school EFL teachers to help their students become autonomous?

5. What are EFL teachers' suggestions for autonomy promotion in technical schools?

\section{Method}

\subsection{Participants}

Participants in the present study were 265 students and 89 EFL teachers at secondary technical schools in Menoufia and Gharbia governorates in Egypt. Students' age ranged between 15 and 19 while teachers' age were between 39 and 53. Teachers' experience in technical schools ranged from 11 to 30 years. All participants (teachers and students) were Egyptians and their mother tongue was Arabic. Table 1 presents participants' gender and school type.

Table 1. Demographic information of participants

\begin{tabular}{llcc}
\hline \multicolumn{1}{c}{ Variables } & \multicolumn{2}{c}{ Participants } \\
\cline { 3 - 4 } & & Teachers & Students \\
\hline Gender & Males & 36 & 113 \\
\cline { 2 - 4 } & Females & 53 & 152 \\
\hline Schools & Industrial & 28 & 72 \\
\cline { 2 - 4 } & Commercial & 20 & 64 \\
\hline
\end{tabular}




\begin{tabular}{llcc}
\hline Hospitality & 19 & 59 \\
\cline { 2 - 3 } Agriculture & 22 & 70 \\
\hline Total & 89 & 265 \\
\hline
\end{tabular}

As shown in Table 1, 42.6\% of the students were males and $57.4 \%$ were females. As for teachers, males were $40.4 \%$ and females were $59.6 \%$. As for specialization, the highest number of participants was from industrial schools followed by agriculture schools succeeded by commercial and then hotels and hospitality schools.

\subsection{Instruments}

This study adopted the mixed-methods approach to consolidate the validity and reliability of the study. Quantitative data were collected by means of two questionnaires; one for students and the other for teachers. Besides, the qualitative data were gathered through structured interviews with the teachers.

\subsubsection{Student Questionnaire}

This questionnaire was adapted from Arfae (2017), Parmis (2015), and Borg and Al-Busaidi (2012). Items rating was 3 -point Likert scale ( $3=$ agree, $2=$ unsure, and $1=$ disagree). The first section of the questionnaire reveals the demographic information of the students; whereas the second section explores learner autonomy in language teaching and learning and is composed of 26 items. These items explore students' perceptions according to the 10 dimensions of the teacher questionnaire as specified by Borg and Al-Busaidi (2012). All the items were translated into Arabic to facilitate students' understanding.

\subsubsection{Teacher Questionnaire}

The teacher questionnaire was adapted from Borg and Al-Busaidi (2012). The original questionnaire consisted of five sections. Section 1 is concerned with the technical, psychological, sociocultural and political dimensions of learner autonomy in addition to the influence of age, proficiency and culture on learner autonomy. Section 1 also includes the perception of teacher role in promoting autonomy, learner-centeredness and benefits of autonomy. Section 2 investigates teachers' views about the desirability and feasibility of learner autonomy. Section 3 explores teachers' beliefs about the extent to which they regard their learners autonomous. The fourth section provides demographic information about teachers. The last section checks teachers' interest in further participation in discussions and workshops.

Due to the inflexible nature of curriculum development in Egyptian technical education, which doesn't take teachers' views into consideration, the present study adopted only the first and the fourth sections of the original questionnaire. The adapted questionnaire starts with the demographic information section. Then the other section consisted of 37 items rated on five-point Likert scale (5= strongly agree, $4=$ agree, $3=$ unsure, $2=$ disagree, $1=$ strongly disagree) to investigate teachers' beliefs about learner autonomy. 


\subsubsection{Teacher Interview}

Interviews were conducted after administering the teacher questionnaire as it is regarded as a more powerful tool for eliciting narrative data that allows researchers to investigate people's perception and views about the items examined in the questionnaire in greater depth (Alshenqeeti, 2014). Structured interview was conducted with 10 of the participated teachers. The participants had to answer eight questions divided into two parts. The first part explored teachers' overall perceptions about learner autonomy. The second part investigated their perceptions of autonomy in technical education. Interview questions were adapted from Parmis (2015).

Out of the 10 interviewees, 4 were males and 6 were females. They voluntarily accepted to be interviewed after responding to the questionnaire. From industrial schools, 3 participants were interviewed, 3 from agriculture schools, 2 from commercial schools and 2 from hospitality schools. Their experience ranged from 13 to 25 years; whereas their ages were between 42 and 51 .

The content validity of the questionnaires and the interview questions was checked by submitting the instruments to jurors in TEFL. To measure the internal reliability of the questionnaires, they were piloted to a group of teachers and students in technical schools other than the ones participated in this study. Cronbach's alpha was calculated for the whole teacher questionnaire and found to be (.90); while total reliability for student questionnaire was (.87). This indicates high internal consistency.

\subsection{Procedures}

The procedures of the present study were twofold. First, the questionnaires were administered to both EFL students and teachers. Second, teachers' interviews were conducted. Starting with student questionnaire, the researchers distributed it to students at the second semester of the academic year 2017/2018 at some technical schools in Gharbiya and Menoufia. This step took place in five days successively. Each researcher with the help of a teacher in the target schools conducted a 45-minute session with the students. The session started with a 10-minute orientation, in which the researchers simply explained the purpose of the study, the nature of the questionnaire, and the indication of the five-point Likert scale and how students can rate items. Students took 35 minutes to complete the questionnaire. The same procedures and amount of time were applied to teacher questionnaire. The interviews were conducted individually by the second researcher. Each interview lasted about 10 minutes and was audio recorded.

\section{Data Analysis and Findings}

The mixed methods approach was used in the present study to verify quantitative findings with qualitative ones. Quantitative data were analyzed through using SPSS to calculate descriptive statistics; whereas qualitative data were transcribed verbatim to categorize data. Data were coded under these themes: The definition of autonomy, characteristics of autonomous learners, 
importance of autonomy in language learning as well as teaching, degree of technical students' autonomy as perceived by teachers, actual autonomy-boosting instructional practices, challenges, and suggestions. An independent coder with the two researchers agreed on the codes and analyzed the responses. The inter-coder reliability was checked and the reliability index was (.89); which indicates high reliability. The findings will be organized in response to the research questions.

\section{Q1: How do Egyptian students in technical schools perceive autonomy in language learning?}

Among technical students in Egypt there was a positive attitude toward learner autonomy and its benefits in language learning. Students' responses to the items of the questionnaire revealed their awareness of learner autonomy and the practices that boost it as shown in Table 2.

Table 2. escriptive statistics of technical, psychological, social and political dimensions in student questionnaire

\begin{tabular}{|c|c|c|c|}
\hline Dimension & Items & $\mathbf{M}$ & SD \\
\hline \multirow[t]{4}{*}{ Technical } & $\begin{array}{l}\text { 3. Learner autonomy is promoted by practicing English outside the } \\
\text { class (such as: use self-study materials, speaking to other people in } \\
\text { English) }\end{array}$ & 2.56 & .732 \\
\hline & $\begin{array}{l}\text { 4. Autonomy is promoted through using the internet and computer to } \\
\text { study and improve English. }\end{array}$ & 2.60 & .694 \\
\hline & $\begin{array}{l}\text { 6. Learner autonomy is promoted through using the library to improve } \\
\text { English. }\end{array}$ & 2.52 & .779 \\
\hline & Overall mean & \multicolumn{2}{|c|}{2.56} \\
\hline \multirow[t]{5}{*}{ Psychological } & $\begin{array}{l}\text { 5. To become autonomous, learners need to note their strengths and } \\
\text { weaknesses in learning English and improve them. }\end{array}$ & 2.32 & .803 \\
\hline & 8. Learner autonomy implies finding ways to learn English. & 2.14 & .664 \\
\hline & $\begin{array}{l}\text { 9. To become autonomous, learners need to evaluate their progress in } \\
\text { learning English. }\end{array}$ & 2.27 & .831 \\
\hline & $\begin{array}{l}\text { 18. To become autonomous, learners have to find and correct their } \\
\text { own mistakes in learning English. }\end{array}$ & 2.43 & .623 \\
\hline & Overall mean & \multicolumn{2}{|c|}{2.29} \\
\hline Social & $\begin{array}{l}\text { 7. Autonomy is fostered when learners take regular opportunities to } \\
\text { complete tasks alone. }\end{array}$ & 2.66 & .611 \\
\hline
\end{tabular}


17. Autonomy is fostered when learners engage in cooperative group $\quad 2.43 \quad .781$ work activities.

23. Autonomy is fostered when learners learn English with the help $\quad \begin{array}{lll}2.15 & .911\end{array}$ and guidance of the teacher.

\section{Overall mean}
$\begin{array}{llll}\text { Political } & \text { 1. Learner autonomy requires learners to make decisions and set goals } & 2.14 & .864\end{array}$ of learning English.

16. Learner autonomy requires learners to make decisions concerning $\quad 2.10 \quad .658$ topics, activities, assessment tools, and learning materials.

Vast majority of the students (90\%) regarded the technical dimension of autonomy with its independent practices as the most important part. Self-paced techniques like practicing English outside the classroom and using library, computers and internet were the most agreed upon strategies among all autonomy practices. However, 54\% of the students were not sure that autonomy involves the ability to search for new ways to learn English as presented by item 8 in the psychological subsection. It is noteworthy that more than half of the students highlighted the importance of self-evaluation and self-correction as expressed by items 5, 9 and 18 .

The majority of students (70-74\%) agreed with items 7, 17 and 23 in the social dimension which examine students' abilities and skills to learn alone, with the help of the teacher or in groups. As for the political dimension, about half of the students agreed that autonomy requires making decisions and setting goals for learning in general whereas $56 \%$ were unsure about making decisions concerning topics, assessment tools and learning materials.

Figure 2 displays the means of students' perceptions of teacher's roles represented by items 11 , 22,24 and 26. 


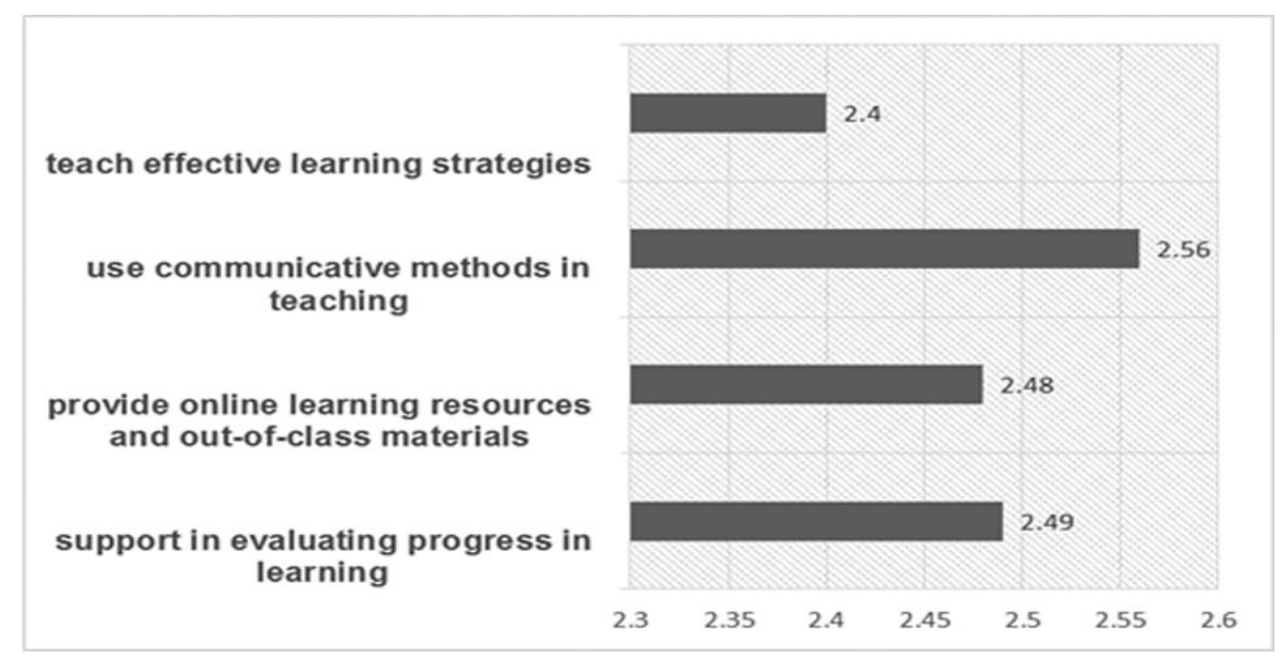

Figure 2. Means of students' perceptions of teacher's roles

As shown in Figure 2, the means of this domain ranged from 2.40 to 2.56; which revealed that most of the students believed that learner autonomy requires the teachers to use communicative methods, peer and self-evaluation, online learning resources and effective learning strategies.

Additional insights were found in the student's perception of the effect of age and proficiency level on learner autonomy. Students believed that age and proficiency have no effect on autonomy whereas they were unsure about the effect of culture. These findings are displayed in Table 3.

Table 3. Descriptive statistics of culture, age and proficiency dimensions in student questionnaire

\section{Items}

M SD

12. Autonomy in learning English can be developed regardless of the proficiency $\quad \begin{array}{lll}1.80 & .955\end{array}$ level.

13. Autonomy in learning English can be developed regardless of the age.

14. Autonomy in learning English can be developed regardless of the cultural background.

20. Learner autonomy is only possible with western (non-Arab) learners.

21. Learner autonomy is only possible with adult learners.

$2.08 \quad .926$

25. Promoting autonomy is easier with beginners than with proficient learners.

$1.65 \quad 909$ 


\section{Macrothink}

Besides, students were in favor of learner-centered classroom. Students highly agreed with item 15 "autonomy in learning English can be achieved in learner-centered context" with mean of 2.66. Comparatively, $48 \%$ of the students disagreed with item 19 "autonomy can be promoted when teachers maintain the traditional teacher-centered style" with mean of 1.94 .

Items 2 and 10 explored students' perceptions of the benefits of autonomy in learning English. About $60-64 \%$ of respondents agreed that "learners can learn English more effectively when they take responsibility for their own learning" $(M=2.71)$ and that "learners who lack autonomy are not likely to be effective language learners" $(M=2.60)$.

\section{Q2: How do Egyptian EFL teachers in technical schools perceive autonomy?}

When descriptive data were analyzed, results displayed that EFL teachers in this study had an overall awareness of the concept of learner autonomy. Such awareness was clarified through the interview as the participants defined autonomy as:

"The students' ability to find information and learn without a teacher or with minimum help from others".

“Autonomy means students' capabilities to monitor their learning, using adults' support and technology, and having a goal for learning."

“Autonomy means taking responsibility for learning inside and outside schools."

Results also revealed teachers' positive attitude toward the effectiveness of autonomy in language learning. All interviewees asserted that autonomy is very helpful for students and teachers. A participant pointed out:

"If the students are autonomous, this will save my time and effort and encourage me to find out new communicative techniques to create student-centered environment".

Overall comparison of the first four dimensions in the teacher questionnaire indicated that teachers regarded all aspects of autonomy as important; however the degree of importance differs from that of the students. As displayed in Table 4, teachers agreed upon the social dimension as the most important aspect $(M=3.95)$ in enhancing learner autonomy followed by the technical dimension then the psychological and the political dimensions $(M=3.90,3.50 \&$ 3.49 respectively).

Table 4. Descriptive statistics of technical, psychological, social and political dimensions in teacher questionnaire

$\begin{array}{lccc}\text { Dimension } & \text { Items } & \text { M } & \text { SD } \\ \text { Technical } & \text { 2. Independent study in the library is an activity which develops } & 4.31 & .899\end{array}$


learner autonomy.

6. Autonomy can develop most effectively through learning outside $\quad \begin{array}{lll}4.27 & 1.020\end{array}$ the classroom.

21. Learner autonomy is promoted by independent work in a $3.91 \quad 1.154$ self-access center.

31. Out-of-class tasks which require learners to use the internet promote learner autonomy.

Overall mean 3.90

$\begin{array}{lllllll}\text { Psychological 11. Confident language learners are more likely to develop } & 4.36 & .772\end{array}$ autonomy than those who lack confidence.

29. Learning how to learn is key to developing learner autonomy. $\quad \begin{array}{lll}4.43 & .824\end{array}$

32. The ability to monitor one's learning is central to learner $4.17 \quad .742$ autonomy.

33. Motivated language learners are more likely to develop learner $\quad 4.58 \quad .720$ autonomy than learners who are not motivated.

37. To become autonomous, learners need to develop the ability to $4.11 \quad 1.122$ evaluate their own learning.

Overall mean

Social

3. Learner autonomy is promoted through regular opportunities for

$3.17 \quad .801$ learners to complete tasks alone.

16. Learner autonomy is promoted through activities which give $3.99 \quad 1.182$ learners opportunities to learn from each other.

19. Learner autonomy is promoted by activities that encourage learners to work together.

25. Co-operative group work activities support the development of $\quad \begin{array}{lll}4.33 & .836\end{array}$ learner autonomy.

30. Learning to work alone is central to the development of learner $\quad 4.11 \quad .832$ autonomy.

Overall mean

$\begin{array}{llll}\text { Political } & \text { 4. Autonomy means that learners can make choices about how they } & 3.34 & 1.331\end{array}$ learn. 
7. Involving learners in decisions about what to learn promotes $3.48 \quad 1.289$ learner autonomy.

14. Learner autonomy is promoted when learners have some choice $3.55 \quad 1.197$ in the kinds of activities they do.

22. Learner autonomy is promoted when learners are free to decide $\quad 3.78 \quad 1.277$ how their learning will be assessed.

27. Learner autonomy is promoted when learners can choose their $3.28 \quad 1.323$ own learning materials.

Overall mean

Concerning the technical perspective, more than half of the teachers were in favor of developing autonomy through out-of-class activities and using external resources like the library and the internet. It is noteworthy that the highest agreed upon items were found in the psychological dimension which examines students' motivation and learning how to learn. About $92 \%$ of the participants agreed that motivated learners are more able to develop autonomy than their less-motivated peers. In addition, $80 \%$ of the teachers agreed that learners' ability to monitor and evaluate their learning is central to learner autonomy. This finding was confirmed when the teachers were interviewed as they all agreed that autonomous learners are passionate for learning, independent, intelligent, good users of technology, motivated, decision-makers, selective of what and how to learn, and productive. A teacher stated:

"When I played a video or audio in English, autonomous learners try hard to find ways to understand before asking me. For example, they guess from context, use background knowledge or read subtitles".

In the social dimension, about $70 \%$ of the teachers supported activities that encourage cooperative group work as well as working alone as means to foster autonomy. Regarding the political dimension, the majority of the teachers sustained learners' involvement in decisions about learning activities and assessment. However, two-thirds of the interviewees reported that their students cannot make a right learning decision alone and being there is essential for the welfare of the students especially in technical schools. A teacher justified:

"Students at technical and vocational schools are quite teacher-dependent as they lack understanding of the concept and strategies to be autonomous in learning a language. They are demotivated and aimless". 
Similarly, teachers perceived that their role in enhancing learner autonomy is fundamental. Most of the teachers agreed that learner autonomy could not be developed without the help of the teacher. All the teachers in the interview asserted this finding and a teacher commented:

"It is our responsibility to teach our students how to be autonomous. I think we as teachers should start with ourselves and be autonomous". He added: "Though I face many problems to develop autonomy, I try to identify my students' learning styles and provide them with strategies to learn independently".

This finding was asserted by teachers' responses to items 8, 18, 24 and 35 in the teacher questionnaire. Figure 3 depicts the means of these items.

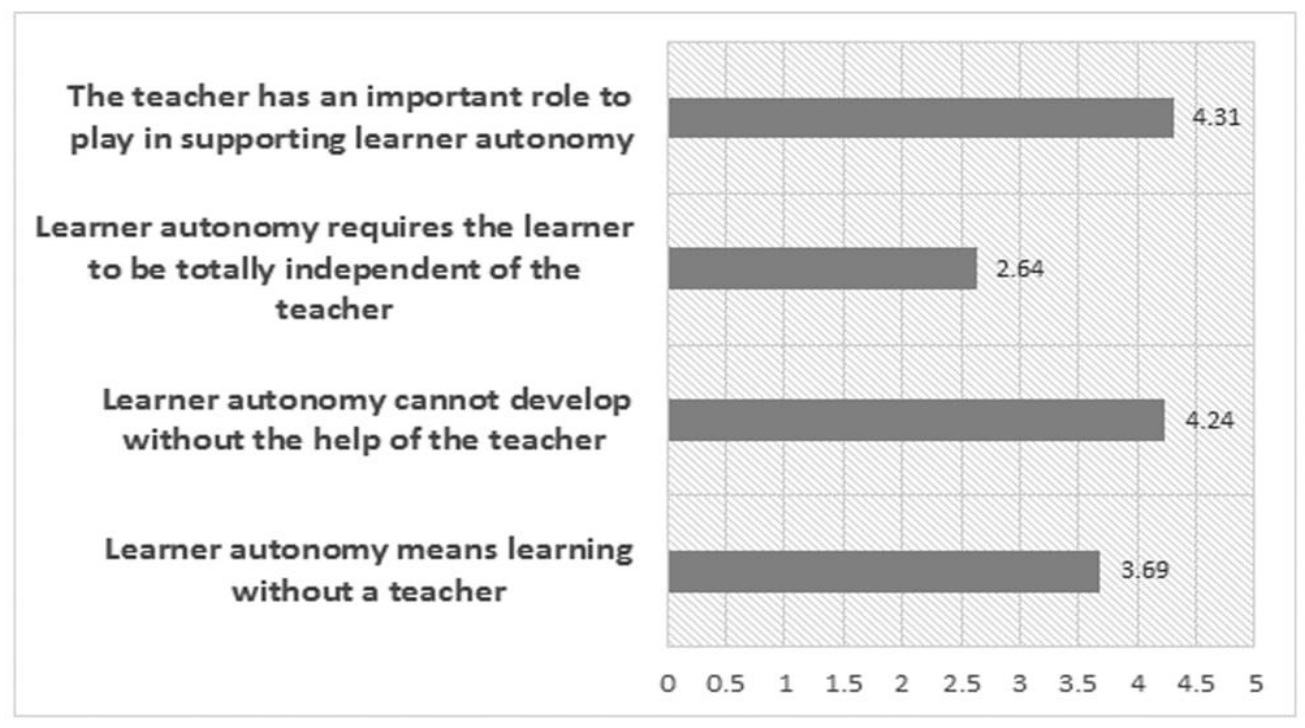

Figure 3. Means of teachers' perceptions of their roles

Although the means ranged between 2.64 and $4.31 ; 53.9 \%$ of the teachers disagreed that "learner autonomy requires the learner to be totally independent of the teacher".

Most of the teachers were unsure about the effect of culture on autonomy. They believed that learners can promote autonomy at any age. Moreover, teachers believed that proficient learners are more capable of developing autonomy than less-proficient learners. These relationships are represented in numbers in Table 5. 
Table 5. Descriptive statistics of culture, age and proficiency dimensions in teacher questionnaire

\begin{tabular}{lcc}
\hline Items & M SD \\
\hline \begin{tabular}{l} 
1. Language learners of all ages can develop learner autonomy. \\
\hline $\begin{array}{l}\text { 9. It is harder to promote learner autonomy with proficient language learners } \\
\text { than it is with beginners. }\end{array}$
\end{tabular} & 3.25 & 1.282. \\
\hline
\end{tabular}

10. It is possible to promote learner autonomy with both young language

$3.22 \quad 1.250$ learners and with adults.

13. Learner autonomy can be achieved by learners of all cultural backgrounds. $\quad 3.01 \quad 935$

20. Learner autonomy is only possible with adult learners.

$2.87 \quad 1.160$

23. Learner autonomy is a concept which is not suited to non-Western learners. $3.40 \quad 1.184$

26. Promoting autonomy is easier with beginning language learners than with $\begin{array}{lll}2.71 & 1.245\end{array}$ more proficient learners.

34. The proficiency of a language learner does not affect their ability to develop $3.15 \quad 1.336$ autonomy.

The majority of teachers also advocated learner-centered classroom as a key to enhance autonomy if compared to the traditional teacher-centered learning environment. This is manifested in their responses to item 15 "learner autonomy cannot be promoted in teacher-centered classrooms" and item 17 "learner autonomy implies a rejection of traditional teacher-led ways of teaching" with means of 4.22 and 4.19 respectively. Likewise, two-thirds of the participants agreed with item 28 "learner-centered classrooms provide ideal conditions for developing learner autonomy" (M=3.58).

Additionally, teachers believed that "Individuals who lack autonomy are not likely to be effective language learners", and "learner autonomy allows language learners to learn more effectively than they otherwise would" that is due to the belief that "learner autonomy has a positive effect on success as a language learner". This finding is represented by items 5, 12 and 36 in the teacher questionnaire with means of 3.60, 3.97 and 4.04 respectively.

\section{Q3: To what extent are technical school EFL students autonomous? What are the reasons?}

Results from the interview showed that $70 \%$ of the teachers claimed that students in their schools lack autonomy in learning English. Teachers in industrial schools indicated that less 
than one-third of students in Electricity track classes are autonomous, though they lack proper strategies to foster their autonomy when learning English.

Analysis of teachers' responses to the interview questions yielded several reasons for lack of autonomy among technical school EFL students. Reasons were supported by teachers' quotes:

a. Lack of awareness of the concept of autonomy

"Generally, students at technical schools lack understanding of the concept and strategies to be autonomous in learning a language".

b. Low proficiency in English

"Almost all the students here are very poor at English. The only exception can be found in Electricity section as students' percentages in joining this stream are higher than their counterparts in other streams and technical schools".

\section{c. Lack of motivation and goals to learn English}

"Students are demotivated and aimless when it comes to English if compared to other practical subjects".

Q4: What are the challenges that face technical school EFL teachers to help their students become autonomous?

Teachers' responses to this question revealed various barriers: Large class size, lack of facilities and resources, students' incapability to shoulder responsibility for their own learning, teachers' insufficient training to promote autonomy, lack of support from administration, limited time to teach learner autonomy, low proficiency level of English for the majority of students in technical schools, limited exposure to English outside the class, irrelevant and outdated textbooks, and the dominance of teacher-centered culture in the Egyptian society. Three teachers commented:

"I believe that developing learner autonomy is difficult in large classes with limited instruction time. Also students lack the motivation to learn English and only study for the test".

"Limited proficiency affects autonomy negatively; proficient students are more likely to be autonomous".

"I think students in technical schools are not ready to be responsible for their learning and they expect the teacher to spoon-feed them. Parents and administrators if not teachers will be against this approach because they have no clear idea about its importance".

\section{Q4: What are technical school EFL teachers' suggestions for promoting learner autonomy?}

Analyzing teachers' responses in the interview provided the following suggestions: 
Raising students' awareness with autonomy at early stages.

Teaching students how and why to learn.

Training EFL teachers themselves to be autonomous.

Preparing EFL materials to enhance learner autonomy in class.

Giving more freedom to teachers to adjust course materials to meet students' needs.

Providing (technological) facilities and resources.

Holding orientation sessions for school staff and parents to raise their awareness of autonomy.

\section{Discussion}

The present study gives valuable insights to improve EFL learning and teaching in technical education in Egypt. The findings of the study revealed that both students and teachers at technical schools had awareness of the concept of autonomy and the characteristics of the autonomous learner. They also possessed a positive attitude toward its effectiveness in learning in general and in EFL learning and teaching in particular. This finding coincides with most of the literature in the field (Brog \& Al-Busaidi, 2012; Al Asmari, 2013).

In addition, the results reflect the importance of motivation in boosting learner autonomy. This finding is in line with Liu's study (2015) that concluded that motivation and autonomy had a high level of positive correlation. Accordingly, similar results were obtained from a study by Bravo et al. (2017) who examined the relationship between levels of motivation and autonomous language learning activities undertaken by the students. Therefore, the researchers of the current study came to the conclusion that there was a significant relationship between students' motivation and their learning autonomy. Concurring results were reported in other relevant studies (Fukuda et al., 2011; Liu, 2012).

Learning to learn was revealed to be a very influencing factor in learner autonomy. This skill was exemplified by the students' metacognitive abilities to monitor, control and evaluate their own learning. This result correlates with various studies. Sariçoban (2012) aimed at identifying the effect of metacognitive strategies in promoting learner autonomy by investigating this relationship in EFL reading. He found a significant correlation between metacognitive reading strategies and reading autonomy. A parallel finding was found out in Cao's study (2012), in which he examined the relationship among autonomous learning, metacognitive strategy training and English achievement in web-based environment. The findings displayed that metacognitive strategy training significantly affected English learning in a positive manner. 
Additionally, the teacher role was found out to be of great importance to promote autonomy from the students' and teachers' point of view. Teachers were perceived as a facilitator who guides learners to develop autonomy. Teachers were in support of fostering autonomy by using autonomy-boosting strategies such as communicative methods of teaching and providing extra material and learning resources. Such finding correlates with studies including (Han, 2014; Çakıc1, 2015).

The results of this study highlighted students' and teachers' belief of the positive relationship between proficiency and autonomy. This was the reason behind finding some autonomous EFL students only in Electricity section at the industrial schools. The students in this stream have English proficiency level higher than their colleagues in the other sections. This belief was confirmed by empirical studies in the literature. Dafei (2007) concluded that the students' English proficiency had a significant and positive relationship to their learner autonomy. Coinciding with this result, Myartawan et al. (2013) investigated the correlation between learner autonomy and English proficiency. Results showed that learner autonomy and English proficiency had a significant, strong, and positive relationship.

Furthermore, participants in this study; teachers and students; expressed their uncertainty of the effect of culture on learning autonomy. They believed that learning autonomy can only be promoted in western cultures. This attitude can be a reflection of the educational culture (regulations, curriculum and teaching) in Egypt which doesn't recognize the students' right to have voice and supports the teacher as the authority in the classroom; a culture that affects the learner intellectually and socially. This finding is in line with Missoum (2016) who surveyed a group of teachers and students from the English department at the University of Blida 2, Algeria. He found that although participants hold positive attitudes toward learning autonomy, they were uncertain about the role of Algerian educational and general cultures in enhancing Algerian learners' autonomy. Likewise, further studies concluded that autonomy may be ethnocentric and culturally inappropriate to non-western learners (Ertürka, 2016; Althaqafi, 2017).

By the same token, this study sheds light on an attitudinal problem concerning technical EFL students. They were found out to possess low self-esteem and uncertainty of their ability to take decisions in learning. EFL teachers had a similar view about the students as they perceived them as incapable of being responsible for their own learning. This problem could be a result of the educational culture in Egypt which limits active participation of students in making learning decisions. Possible solutions to resolve this issue include teachers' training on developing learner autonomy and involving learners in decisions about what and how to learn. In addition to this psychological problem, other institutional barriers were reported such as limited time, resources and administrative support which hinder the promotion of learner 
autonomy. This finding was asserted by previous studies (Reinders \& Lazaro, 2011; Borg \& Al-Busaidi, 2012).

\section{Conclusion}

The study explored EFL teachers' and students' perceptions of learner autonomy in learning English in a number of technical schools in Egypt. The data obtained from a questionnaire and interviews have shown that teachers perceived autonomy as a vital factor for the success in language learning and believed that autonomous learners are more effective and motivated. The study also highlighted the importance of the technical, psychological, social and political dimensions in promoting autonomy. Some challenges in implementing learner autonomy in technical schools were identified including lack of preparation, low proficiency level of students and prevalence of teacher-centered culture. Results from analyzing student questionnaire indicated a strong preference for some autonomous approaches in learning English like learning independently outside the class, using online resources, and exchanging ideas with other learners in a learner-centered context. Students also highlighted the importance of teachers in promoting learner autonomy. Neither teachers nor students were sure about the role that culture plays on autonomy.

The present study is limited to the small number of participants (teachers and students) from technical schools in two governorates in Egypt. Therefore, the sample size should be increased and be representative of more governorates to maximize the chance of generalizing findings to other contexts. Research instruments were inclusive to questionnaires and interviews. Other in-depth tools like observation and policy analysis or textbook analysis would help in triangulation of research findings.

\section{Pedagogical Implications and Recommendations}

Several practical implications are drawn from the present study. Teachers should be trained in pre-service and in-service programs on how to promote students' autonomy gradually. To that end, training should focus on raising teachers' awareness of the importance of autonomy, understanding students' needs in learning languages, and cultivating them with methods for increasing individual learning. Teachers have to train students on appropriate learning strategies, encourage cooperative learning, prepare learning resources to support learning outside class, boost students' motivation and confidence, and reinforce positive examples and experiences of students who succeeded in learning English in technical schools. 
Administrators and decision makers should allow teachers more freedom to adapt textbooks to technical school students' needs and overcome institutional barriers that hinder successful growth of learner autonomy. Partnership with agencies like the British Council will contribute to the development of teachers' as well as students' skills and thus their autonomy. Course book designers should create authentic material to incorporate practical and relevant scenarios in the lessons and accommodate content to students' needs in technical schools. More consideration about establishing language laboratories in technical schools and integrate technology in EFL teaching should be given.

Emerging research can investigate the influence of variables like age, gender, experience of teachers on their perceptions of learner autonomy. More studies are needed to examine the correlation between teachers' perceptions of autonomy and their instructional practices. Examining the strategies used by students of high perceptions compared to those of low and mid-perceptions is noteworthy. Additionally, studying the relationship between students' perceptions and their achievement and self-efficacy in English in technical schools will be informative. Further studies need to compare students' perceptions of autonomy from the same/different specializations in technical schools. Moreover, exploring strategies to promote autonomy in EFL classes in technical schools is recommended. Future studies need to identify the professional needs of teachers to enhance their professional development regarding learner autonomy.

\section{References}

Akbarpour-Tehrani, I., \& Wan Mansor, W. F. (2012). The influence of teacher autonomy in obtaining knowledge on class practice. Procedia - Social and Behavioral Sciences, 66, 544-554.

Al Asmari, A. (2013). Practices and prospects of learner autonomy: Teachers' perceptions. English Language Teaching, 6(3), 1-10.

Alhaysony, M. (2016). An investigation of EFL teachers' beliefs and practices of learner autonomy. International Journal on Studies in English Language and Literature (IJSELL), 4(12), 45-59. https://doi.org/10.20431/2347-3134.0412009

Alibakhshi, G., Keikha, A., \& Nezakatgoo, B. (2015). On the feasibility and desirability of learner autonomy from Iranian EFL teachers' perspectives. International Journal of Applied Linguistics and English Literature, 4(6), 141-147.

Alonazi, S. M. (2017). The role of teachers in promoting learner autonomy in secondary 
schools in Saudi Arabia. English Language Teaching, 10(7), 183 - 202.

Alshenqeeti, H. (2014). Interviewing as a data collection method: A critical review. English Linguistics Research, 3, 39-45.

Althaqafi, A. (2017). Culture and learner autonomy: An overview from a Saudi perspective. International Journal of Educational Investigations, 4, 39-48.

Arfae, A, M. (2017). Language learner autonomy in Ontario's ESL context. Electronic Thesis and Dissertation Repository. 5003. Retrieved from: http://ir.lib.uwo.ca/etd/5003

Benson, P. (2011). What's new in autonomy? The Language Teacher, 35(4), 15-18.

Benson, P. (2012). Autonomy in language learning, learning and life. Synergies France, 9, 29-39.

Borg, S., \& Al-Busaidi, S. (2012). Learner autonomy: English language teachers' beliefs and practices. ELT Research Paper, 12-07. London: British Council.

Bravo, J. Intriago, E. Holguín, J. Garzon, G. and Arcia, L. (2017). Motivation and autonomy in learning English as Foreign Language: A case study of Ecuadorian college students. English Language Teaching, 10(2), 100-113.

Çakıc1, D. (2015). Autonomy in language teaching and learning process. İn̈nü Üniversitesi Ĕ̈itim Fakültesi Dergisi, 16(1), 31-42. https://doi.org/10.17679/iuefd.16168538

Cao, Y. (2012). A study of metacognitive strategies in web-based English autonomous learning. International Conference on Management and Education Innovation IPEDR, 37, 66-69. IACSIT Press, Singapore.

Cubukcu, F. (2016). The correlation between teacher trainers' and pre-service teachers' perceptions of autonomy. Proscedia - Social and Behavioral Sciences, 232, 12-13.

Dafei, D. (2007). An exploration of the relationship between learner autonomy and English proficiency. Asian EFL Journal. Retrieved from http://www.asian-efl-journal.com/pta_Nov_07_dd.pdf

Doğan, G. \& Mirici, İ. H. (2017). EFL instructors' perception and practices on learner autonomy in some Turkish universities. Journal of Language and Linguistic Studies, 13(1), 166-193.

Duong, T. (2014). EFL teachers' perceptions of learner autonomy and their classroom practices: A case study. I. J. Education and Management Engineering, 2, 9-17. 
EP-Nuffic. (January, 2015). The Egyptian education system described and compared with the Dutch system (2nd version). The Dutch organization for internationalization in education.

Ertürk, N. O. (2016). Language learner autonomy: Is it really possible? Procedia - Social and Behavioral Sciences, 232, 650-654.

Euromonitor International. (April, 2012). The Benefits of the English Language for Individuals and Societies: Quantitative Indicators from Algeria, Egypt, Iraq, Jordan, Lebanon, Morocco, Tunisia and Yemen. A custom report compiled by Euromonitor International for the British Council.

European Commission: Directorate-General for Education and Culture and International cooperation in education and youth. (2014). TVET College Lecturer Education Annex Report. Luxembourg: Publications Office of the European Union.

Fukuda, S. T., Sakata, H., \& Takeuchi, M. (2011). Facilitating autonomy to enhance motivation: Examining the effects of a guided-autonomy syllabus. Electronic Journal of Foreign Language Teaching, 8(1), 71-86.

Han. (2014). Teacher's role in developing learner autonomy: A literature review. International Journal of English Language Teaching, 1(2), 21-27.

Handoussa, H. (2010). Situation analysis: Key development challenges facing Egypt. Taskforce, United Nations Development Program, Washington, DC. Retrieved from: www.eg.undp.org/content/dam/egypt/.../2010_Sit\%20Analysis_KDCFE_English.pdf

Hasim, Z. and Zakaria, A. R. (2015). ESL teachers' knowledge on learner autonomy. In Knowledge, Service, Tourism \& Hospitality: Proceedings of The Annual International Conference on Management and Technology In Knowledge, Service, Tourism \& Hospitality 2015 (SERVE 2015). CRC Press.

Holec, H. (1979). Autonomy and Foreign Language Learning. Strasbourg, France: Council for Cultural Cooperation.

Ibrahim, M. K, \& Ibrahim, Y. A. (2017). Communicative English language teaching in Egypt: Classroom practice and challenges. Issues in Educational Research, 27(2), 285-313.

Ikonen, A. (2013). Promotion of learner autonomy in the EFL classroom: The students' view (Unpublished master's Thesis). University of Jyvaskyla, Finland.

Jácome, E. P. (2012). Promoting learner autonomy through teacher-student partnership assessment in an American high school: A cycle of action research. Profile: Issues in Teachers' Professional Development, 14(2), 145-162. 
Khoshsima, H. \& Rezaeian, F. (2015). Language learner strategies for building EFL learners' autonomy. International Journal of English Language \& Translation Studies, 3(4), 60-73.

Lamb, T. (2010). Assessment of autonomy or assessment for autonomy? Evaluating learner autonomy for formative purposes. In A. Paran \& L. Sercu (Eds.). Testing the untestable in language education, (pp. 98-119). Bristol: Multilingual Matters.

Liu, H. J. (2012). Understanding EFL undergraduate anxiety in relation to motivation, autonomy, and language proficiency. Electronic Journal of Foreign Language Teaching, 9(1), 123-139.

Liu, H. J. (2015). Learner autonomy: The role of motivation in Foreign Language Learning. Journal of Language Teaching and Research, 6(6), 1165-1174.

Loveluck, L. (March 2012). Background Paper Education in Egypt: Key Challenges Middle East and North Africa Programme. Chatham House.

Missoum, M. (2016). Culture and Learner Autonomy. Journal of Arts and Languages University of Blida, Algeria, 1-14.

Myartawan, I. P., Latief, N. W., \& Suharmanto, M. A. (2013). The correlation between learner autonomy and English proficiency of Indonesian EFL college learners. TEFLIN Journal, 24(1), 63-81.

Najmeh, N., Abbas, E., Hossein, V., and Zahra, A. (2015). Promoting learner autonomy in an Iranian EFL high school context: Teachers' practices and constraints in focus. International Journal of Research Studies in Language Learning, 4(3), 91-105.

Nguyen, N. T. (2014). Learner autonomy in language learning: teachers' beliefs (Unpublished doctoral dissertation). Queensland University of Technology, Australia.

Parmis, F. (2015). Teachers' and students' perceptions of learner autonomy in the ELT department at Eastern Mediterranean University (Unpublished master's thesis). Eastern Mediterranean University, Famagusta: North Cyprus.

Reinders, H., and Lazaro, N. (2011). Beliefs, identity and motivation in implementing autonomy: The teachers' perspectives. In G. Murray, X. Gao, \& T. Lamb. (Eds.), Identity, motivation, and autonomy in language learning (pp. 125-142). Bristol: Multilingual Matters.

Sariçoban, A. (2012). Metacognitive strategies and learner autonomy in EFL reading. Modern Journal of Language Teaching Methods, 2(2), 45-68.

Shahsavari, S. (2014). Efficiency, feasibility and desirability of learner autonomy based on 
teachers' and learners' point of views. Theory and Practice in Language Studies, 4(2), 271-280.

Szőcs, K. (2015). Hungarian language teachers' perceptions of language learning autonomy. In S. L. Krevelj \& J. Mihaljević Djigunović (Eds.), UZRT 2014: Empirical Studies in Applied Linguistics (pp.70-80). Zagreb: FF press.

Tran, T. Q., \& Duong, T. M. (2018). EFL learners' perceptions of factors influencing learner autonomy development. Kasetsart Journal of Social Sciences, 1, 1-6. https://doi.org/10.1016/j.kjss.2018.02.009

UNESCO. (2012). World TVET Database Egypt. UNESCO-UNEVOC International Centre for Technical and Vocational Education and Training, Compiled by UNESCO-UNEVOC.

Yasmin, M., \& Sohail, A. (2018). Realizing learner autonomy in Pakistan: EFL teachers' beliefs about their practices. International Journal of English Linguistics, 8(2), 153-162. https://doi.org/10.5539/ijel.v8n2p153

Yunus, M., \& Arshad, N. (2015). ESL teachers' perceptions toward the practices and prospects of autonomous language learning. Asian Social Science, 11(2), 41-51.

Zou, L. (2017). On the cultivation of students' English autonomous learning ability in vocational colleges in Leshan City, Sichuan, China. Journal of Language Teaching and Research, 8(6), 1156-1160. https://doi.org/10.17507/jltr.0806.1

\section{Copyright Disclaimer}

Copyright for this article is retained by the author(s), with first publication rights granted to the journal.

This is an open-access article distributed under the terms and conditions of the Creative Commons Attribution license (http://creativecommons.org/licenses/by/3.0/). 